\title{
Predicting land-surface climates-better skill or moving targets?
}

\author{
A. Henderson-Sellers, ${ }^{1}$ P. Irannejad, ${ }^{1}$ K. McGuffie, ${ }^{2}$ and A. J. Pitman ${ }^{3}$ \\ Received 23 March 2003; revised 18 May 2003; accepted 20 June 2003; published 31 July 2003.
}

[1] Uncertainty in the prediction of continental surface climates is identified by the Intergovernmental Panel on Climate Change (IPCC) as limiting our confidence in projecting future climates. To reduce this uncertainty, the Atmospheric Model Intercomparison Project (AMIP) Diagnostic Subproject 12 (DSP 12) and the Project for Intercomparison of Land-surface Parameterisation Schemes (PILPS) have used a substantially improved experimental design, coupled with a greater variety of land-surface schemes (LSSs) represented in AMIP II, to investigate whether the thirty years of effort in land surface modelling has led to improvements in simulations of continental surface processes. In AMIP II, we find a clear chronological sequence of: First generation 'no canopy'; second generation 'SiBlings'; and 'recent schemes'. We conclude that three decades have improved continental surface modelling capability but that full confidence in our ability to project land-surface quantities using climate models remains elusive, in part due to uncertainties in surface observations. INDEX TERMS: 0315 Atmospheric Composition and Structure: Biosphere/ atmosphere interactions; 1833 Hydrology: Hydroclimatology; 3307 Meteorology and Atmospheric Dynamics: Boundary layer processes; 1866 Hydrology: Soil moisture; 1620 Global Change: Climate dynamics (3309). Citation: Henderson-Sellers, A., P. Irannejad, K. McGuffie, and A. J. Pitman, Predicting landsurface climates-better skill or moving targets?, Geophys. Res. Lett., 30(14), 1777, doi:10.1029/2003GL017387, 2003.

\section{Energy Partition at the Land Surface}

[2] Two key processes must be encapsulated by the landsurface component of a climate model: The partitioning of available energy between sensible and latent heat and the partitioning of available water between evaporation and runoff. The quantification of improvements in land-surface simulation requires isolating the role of differences in the atmospheric forcing (rainfall, incoming solar radiation etc.) from the changes in model parameterisations and from the feedbacks between atmospheric and land-surface processes [Pitman et al., 1999]. We use the AMIP II Atmospheric General Circulation Models' (AGCMs') results because the experiments are very well constrained in terms of experimental design and model results have been quality controlled [Gates, 1992; Gates et al., 1999]. As our aim is to identify the overall strengths and weaknesses in the community's land-surface models and strategies against a back-

\footnotetext{
${ }^{1}$ ANSTO Environment, Menai, Australia.

${ }^{2}$ Department Applied Physics, UTS, Sydney, Australia.

${ }^{3}$ Department Physical Geography, Macquarie Univ., Sydney, Australia.
}

Copyright 2003 by the American Geophysical Union. 0094-8276/03/2003GL017387\$05.00 ground of imperfect validation data, we do not identify individual models.

[3] The simulated 17-year mean latent heat flux (LH) and sensible heat flux (SH) of 20 AMIP II AGCMs (letters A$\mathrm{T}$ ) and three reanalyses are compared globally (GLS) and for eight de Martonne climates in Figure 1. The diagonal lines show the location of the mean $\mathrm{LH}+\mathrm{SH}$ of all models (solid) and the reanalyses (dashed). (The de Martonne [1948] aridity index is in the form $I_{a}=\bar{P} /(\bar{T}+10)(\bar{P}=$ mean annual precipitation $(\mathrm{mm}) ; \bar{T}=$ mean air temperature $\left({ }^{\circ} \mathrm{C}\right)$ ) plus 'Polar' below temperatures of $-5^{\circ} \mathrm{C}$ [HendersonSellers et al., 2002]. Classification uses the 1979-1995 precipitation from Xie and Arkin [1997] and the average of the three reanalyses (ECMWF, NCEP-NCAR and NCEPDOE) near-surface air temperature.) Scatter along the diagonal is due to differences in partitioning the surface available energy $\left(E_{a}\right)$ into $\mathrm{LH}$ and $\mathrm{SH}$. Scatter perpendicular to the diagonals is due to different predictions of $E_{a}$.

[4] On the global average (GLS), $E_{a}$ for 11 of the AGCMs is within the range of the reanalyses but for the eight de Martonne climates this changes. Agreement is better with ECMWF (ERA15: Gibson et al., 1997) in wetter and cold climates and with NCEP-DOE [Kanamitsu et al., 2002] in drier climates. In Mediterranean to Humid climates, models' LH lie outside the reanalyses' range because the reanalyses agree well. The long-term mean LH (arrowed) from VIC [Liang et al., 1994] is lower than almost all models and reanalyses.

[5] The horizontal lines in Figure 1 show the magnitude of the energy residual $\left(d E_{a}\right)$ of each model, assuming that the net 17-year change in the surface energy store is negligible, i.e.

$$
d E_{a}=\left(R_{n e t}-S_{m} H\right)-(L H+S H)
$$

where $R_{n e t}$ is surface net radiation and $S_{m} H$ snow melt equivalent energy. For three $\mathrm{AGCMs}(\mathrm{L}, \mathrm{G} \& \mathrm{P}), d E_{a}$ is large. These residuals, which differ by (de Martonne) climates, may be due to an energy flux at the lower soil boundary - a hypothesis not tested here. AGCM P, which fails to close its surface energy budget anywhere, has $\left(R_{n e t}-S_{m} H\right)$ considerably greater than all the reanalyses. Model P's mean downward longwave radiation is around $30 \mathrm{~W} \mathrm{~m}^{-2}$ greater than the AMIP average corresponding to an atmospheric temperature deviation of about $6 \mathrm{~K}$ not found in P's reported fields.

\section{Clusters of Land-Surface Schemes}

[6] Figure 1 shows that some models systematically underestimate $\mathrm{LH}$ (e. g. M), underestimate available energy (e. g. O) or overestimate SH (e. g. Q) (comparative terms such as underestimate and overestimate are used here for descriptive clarity, not to indicate any absolute achieve- 


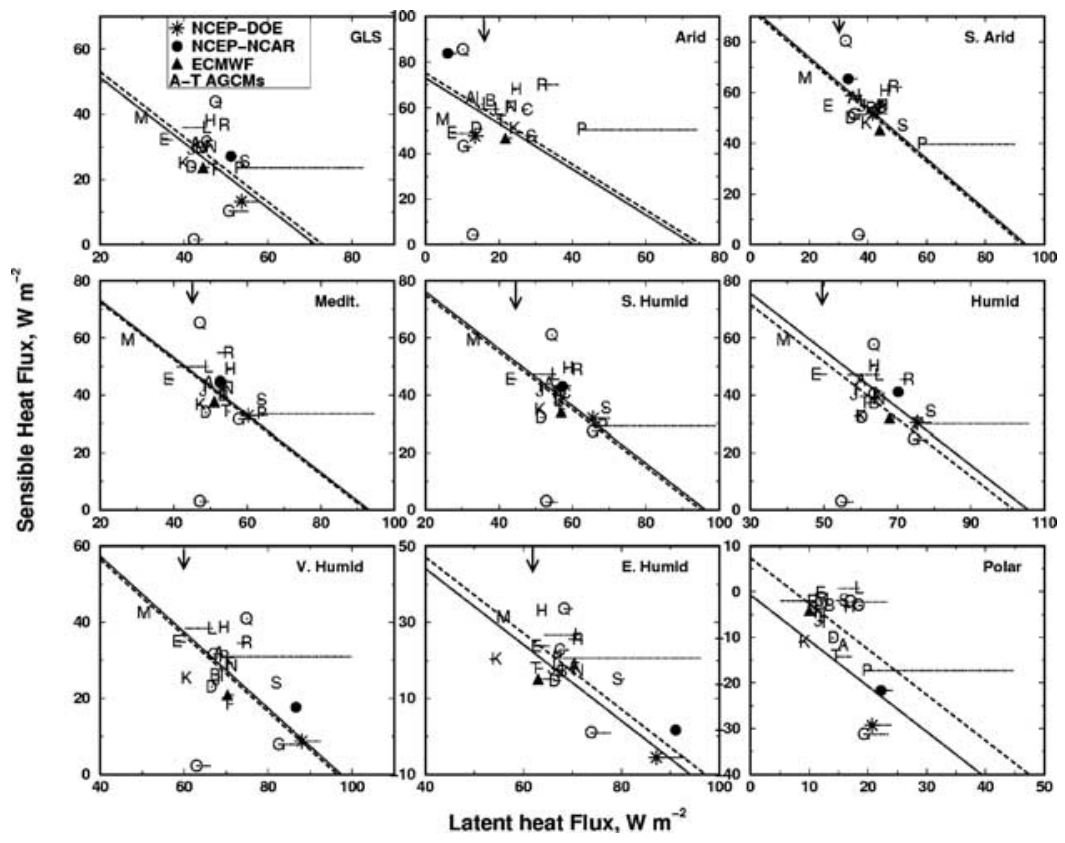

Figure 1. 17-year mean SH and LH of 20 AMIP II models (A-T) and three reanalysis products for all land surfaces (GLS) and the eight de Martonne climates. Diagonal lines are the average LH + SH of all models (solid) and the reanalyses (dashed). Horizontal lines show the AGCMs' surface energy residuals where they are non-zero. Arrows near the top left of the central six panels show the LH estimate as simulated off-line by the VIC land-surface scheme, which, together with the three reanalyses (ECMWF [Gibson et al., 1997], NCEP-NCAR [Kistler et al., 2001] and NCEP-DOE [Kanamitsu et al., 2002]), are validation data - estimates of 'truth'.

ment). Models $\mathrm{M}, \mathrm{Q}$ and $\mathrm{E}$ frequently lie towards the top left (small LH, large $\mathrm{SH}$ ) and $\mathrm{O}, \mathrm{P}, \mathrm{G}$ and $\mathrm{S}$ frequently lie towards the lower part of the distribution (small SH and/or large LH). E and M use SiB [Sato et al., 1989]; Q uses SSiB [Xue et al., 1991]; while both O and P use variants of the bucket hydrology model [Manabe, 1969]. G and S are twolayer soil hydrology models but, like $\mathrm{O}$ and $\mathrm{P}$, they do not model the canopy explicitly. All the LSS Figure 1 outliers are from two groups: A one- or two-layer hydrology with no explicit canopy ('no canopy') and a SiB-based [Sellers et al., 1986] LSS (SiBlings). Model L's LSS is also a SiBling (SSiB: Xue et al., 1991). Unlike the classical bucket [Manabe, 1969], $\mathrm{P}$ and $\mathrm{O}$ introduce a pre-infiltration runoff as a linear or nonlinear function (respectively) of relative soil moisture and do not predict as large LH as the original bucket model [e.g. Shao and Henderson-Sellers, 1996]. The SiBlings' small LH (closest to VIC) is either a result of unfavorable atmospheric forcing or due to the high sensitivity of the canopy resistance of the scheme to atmospheric humidity. Model O's low LH (except Extremely Humid) is due to its abnormally small surface available energy.

[7] Generalizing, variations among the models' LH and $\mathrm{SH}$ are relatively smaller in wetter climates than in drier ones; reanalyses agree more with each other in intermediate climates (but all overestimate LH compared to VIC (The lack of high quality observed global datasets of land-surface variables such as evapotranspiration occurs because they are not directly observable at scales appropriate to atmospheric models. Reanalysis data and pseudo-observations generated by forcing the VIC land-surface scheme off-line and constraining its results by known parameters such as large river discharges are known to have limitations.)). While the twolayer soil models with no explicit canopy (G and S) simulate high LH in almost all climates, the bucket model including canopy resistance (A) simulates much lower LH.

[8] No clustering is evident in surface variables or forcings that match or simply explain these clusters (P. Irannejad, S. Sharmeen, and A. Henderson-Sellers, Importance of land surface parameterization for latent heat simulation in global atmospheric models, submitted to Geophysical Research Letters, 2003). For example, SiBlings do not predict low LH because they are in models from which they derive low surface available energy or low surface available water: $Q$ has large $P_{r}$ and $R_{\text {net }}$ whereas $E, M$ and $L$ have much smaller values of both. Many models have too much downward shortwave radiation at the surface but their net surface energy is less than observed [Henderson-Sellers et al., 1995].

\section{Separating Forcing Effects From Parameterization Differences}

[9] Differences in available moisture and energy in the AGCMs or feedbacks between surface and atmosphere might be responsible for the clustering of models in Figure 1. Figure 2 illustrates the effect of excluding the differences due to energy availability (scatter across the diagonal lines in Figure 1) by scaling $\mathrm{SH}$ and $\mathrm{LH}$ against the reanalysis ensemble $E_{a}$ :

$$
\left\{\begin{array}{l}
L H_{m s}=L H_{m}\left(\frac{E_{a}(r)}{E_{a}(m)}\right) \\
S H_{m s}=S H_{m}\left(\frac{E_{a}(r)}{E_{a}(m)}\right)
\end{array}\right.
$$

where $m, r$ and $s$ stand for model, ensemble reanalyses and scaled, respectively. This scaling assumes linearity in the 


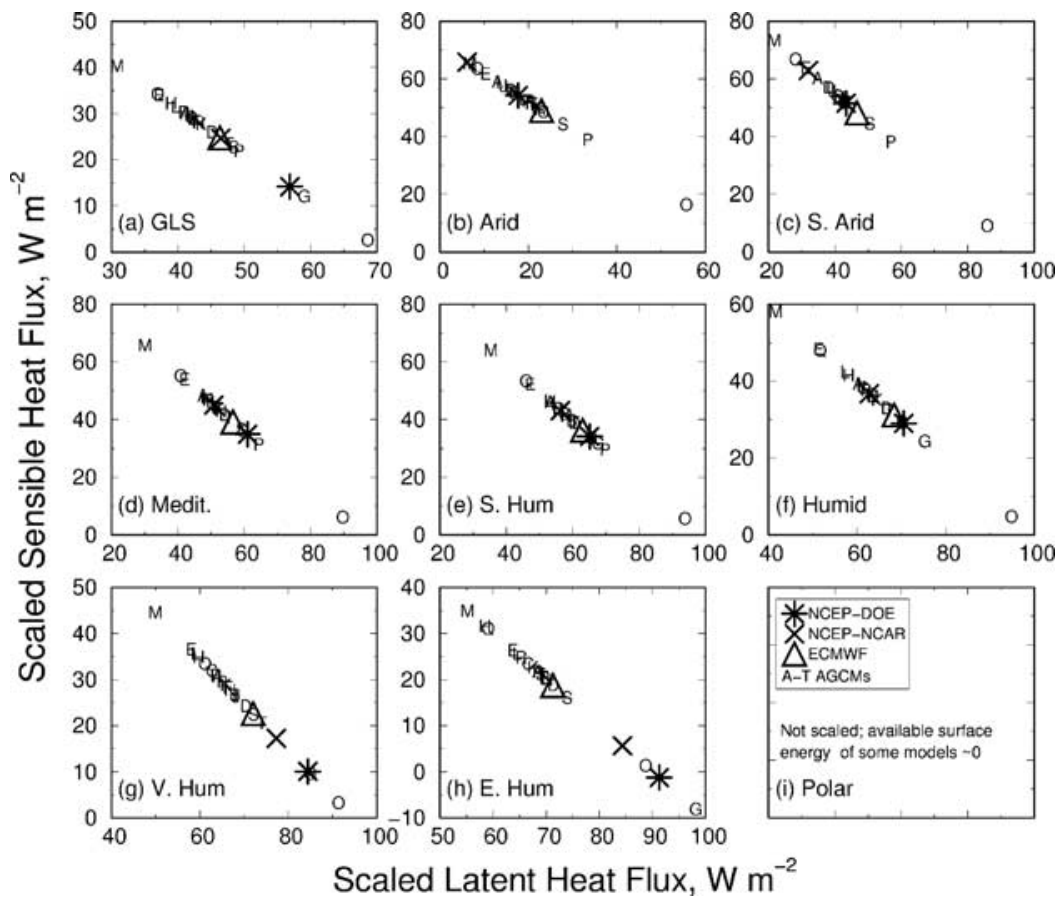

Figure 2. Partitioning of surface energy between scaled SH and LH (ratioed to the average of the three reanalyses) of 20 AMIP II AGCMs (A-T) and three reanalyses for the global land surface (GLS) and seven de Martonne climates. Fluxes for the polar climate are not scaled because the surface energy of many AGCMs is close to zero for this climate.

apportioning of an increment of available energy between sensible and latent heat, but this limitation is unlikely to affect our conclusions. While NCEP-NCAR has similar LH to NCEP-DOE in the two wettest climates (Figure 1), its scaled LH is smaller than NCEP-DOE in all climates. The AMIP II AGCMs are scattered around the NCEP-DOE reanalysis in dry climates; around the NCEP-NCAR reanalysis in the Mediterranean to Humid climates; and around the ECMWF reanalysis in the Very Humid and Extremely Humid climates.

[10] The largest scaled LH globally is associated with LSSs with no explicit canopy. However, the relative position of their scaled LH varies in different climates (possibly due to changes in availability of water) i.e. while $\mathrm{O}$ and $\mathrm{S}$ are among the most evaporating models in all climates, $\mathrm{P}$ has this attribute in drier (Arid to Humid) and $G$ in wetter (Mediterranean to Extremely Humid) climates. The relatively low values of scaled LH predicted by $\mathrm{P}$ compared to $\mathrm{O}$ in more humid climates may be due to its smaller soil depth and hence smaller water holding capacity. E, L, M and $\mathrm{Q}$, which use variants of the $\mathrm{SiB}$ scheme, are among the least evaporating models in almost all climates while $\mathrm{H}$, using a scheme philosophically similar to SiBlings [Dickinson et al., 1986], predicts similarly scaled LHs.

[11] Next, we try to account for precipitation differences among the LSS clusters in Figures 1 and 2. To do this, we adjust the mean LH of each model using observed precipitation and mean reanalyses' surface energy as:

$$
L H_{m s}=L H_{m}\left(\frac{E_{a}(r)}{E_{a}(m)} \times \frac{P_{r}(o)}{P_{r}(m)}\right)
$$

where $L H_{m s}$ is scaled (adjusted) latent heat flux for each cluster, $m$, of LSSs (e.g. SiBlings, reanalyses) using both surface available energy $\left(E_{a}\right)$ and precipitation $\left(P_{r}\right)$ and $r$ and $o$ represent mean reanalyses and observations. The ensemble results for SiBlings, no-canopy schemes and other LSS types are shown in Figure 3a. Artificial correction of soil moisture (nudging) means that the reanalyses' precipitation is not an appropriate measure of available water. An additional adjustment is shown in Figure $3 \mathrm{a}$ by assuming that surface water is conserved and by using the sum of the mean reanalyses' evaporation and runoff as a substitute for precipitation.

[12] Figure 3a clearly confirms the suggestion in Figure 1: On average, even when the very large differences in atmospheric forcing of energy and water are removed, SiBlings evaporate less and no-canopy schemes more than other schemes. On an annual basis over the different climate zones, with only a few exceptions, the differences between the model groups are significant at the 5\% level (using a $t$-test).

\section{Land-Surface Climate Prediction Evolution}

[13] Scaled land-surface fluxes exhibit an evolutionary trend (Figure 3b). The no-canopy schemes evaporate too much because they neglect a canopy resistance; the second generation, SiBlings, emphasize canopy parameterization predicting lower evaporation; and most recent land-surface schemes have achieved compromise, or central tendency. These results show AGCMs using recent LSSs simulate latent heat fluxes close to the ensemble reanalyses, after scaling for differences in surface available energy and water (Figure 3a).

[14] Belief systems pertaining to 'validation' data change. While we hold no brief for particular evaluation data, we note that VIC conserves water in all climates whereas, due to nudging, the reanalyses do not [Roads and Betts, 2000; 

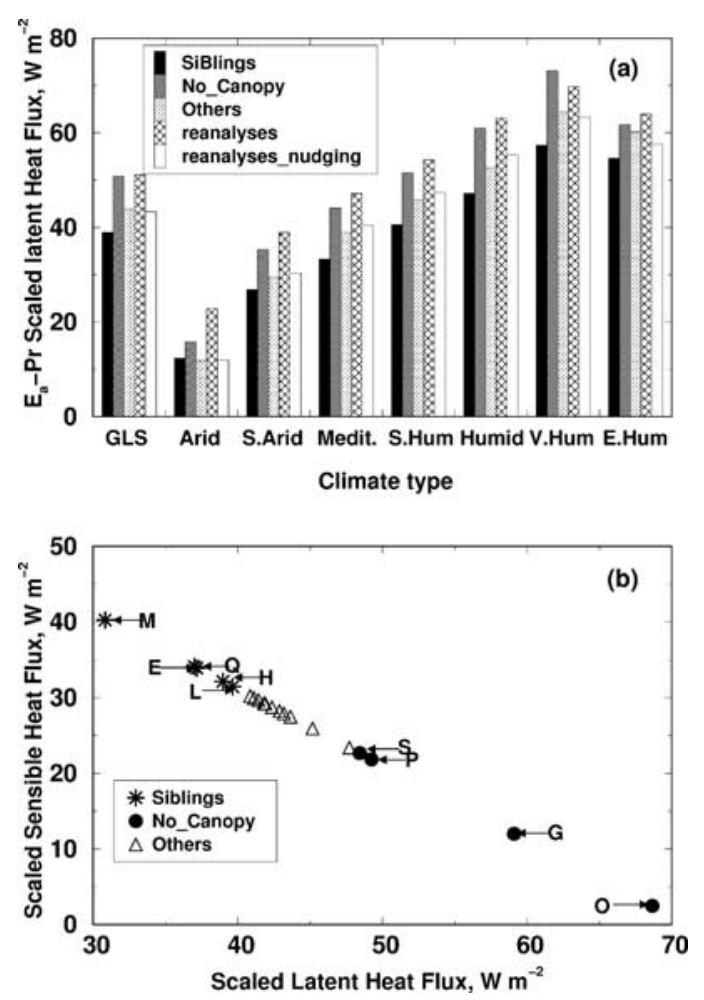

Figure 3. (a) Scaled latent heat flux of the ensemble of reanalyses and AMIP II AGCMs having different types of land-surface schemes based on the observed precipitation and mean reanalyses' surface energy of the same climate types ['reanalyses nudging' shows the scaled LH based on reanalyses' surface available water (evaporation + runoff) rather than precipitation] and (b) GLS panel of Figure 2 reproduced without the 3 reanalyses to highlight the three 'clusters': No canopy (G, S, O, P-lower right), SiBlings (E, M, Q, L, H-top left) and recent schemes (center).

cf. Maurer et al., 2000]. VIC results have been challenged recently, although we employ VIC's water balance mode [Nijssen et al., 2001a, 2001b] not the energy balance mode used by A. Robock et al. (Evaluation of the North American Land Data Assimilation System over the Southern Great Plains during the warm season, submitted to Journal of Geophysical Research, 2003). As all validation datasets have weaknesses at the land surface, convergence to the most recently available may not be desirable.

[15] Our AMIP ensemble results demonstrate that the prediction and partition of land-surface fluxes has evolved over time in a pattern traceable to the manner of implementation of land surface physics; that land-surface parameterization schemes can and do capture the expected wide range of behaviors; and that not all schemes are currently simulating all characteristic climate behaviors equally well.

[16] Acknowledgments. We thank Dr S. Sharmeen for the calculations for this paper and Dr T. Phillips for co-ordination with the PCMDI AMIP II team.

\section{References}

De Martonne, E., Traité de Geographie Physique, 7th ed., Librairie Armand Colin, Paris, 1948.

Dickinson, R. E., A. Henderson-Sellers, P. J. Kennedy, and M. F. Wilson, Biosphere-Atmosphere Transfer Scheme (BATS) for the NCAR Community Climate Model, Tech. Note TN-275+STR, Natl. Cent. for Atmos. Res., Boulder, Colo., 1986.

Gates, W. L., The atmospheric model intercomparison project, Bull. Am. Meteorol. Soc., 73, 1962-1970, 1992.

Gates, W. L., et al., An overview of the results of the Atmospheric Model Intercomparison Project (AMIP I), Bull. Am. Meteorol. Soc., 80, 29-55, 1999.

Gibson, J. K., P. Kallberg, S. Uppala, A. Hernandez, A. Normura, and E. Serrano, ERA description, ECMWF Re-Anal. Proj. Rep. Ser. 1, Eur. Cent. For Medium Range Weather Forecasting, Reading, UK, 1997.

Henderson-Sellers, A., A. J. Pitman, P. K. Love, P. Irannejad, and T. H. Chen, The Project for Intercomparison of Land-Surface (PILPS): Phase 2 \& 3, Bull. Am. Meteorol. Soc., 73, 1962-1970, 1995.

Henderson-Sellers, A., P. Irannejad, S. Sharmeen, A. J. Pitman, and $\mathrm{K}$. McGuffie, Is land-surface climate prediction capability improving?, paper presented at 2nd International AMIP Conference, World Clim. Res. Program, Toulouse, France, 2002.

Kanamitsu, M., W. Ebisuaki, J. Woolen, S. Yang, J. J. Hnilo, M. Fiorino, and J. L. Potter, NCEP/DOE AMIP-II Reanalysis (R-2), Bull. Am. Meterol. Soc., 83, 1631-1643, 2002.

Kistler, R., et al., The NCEP-NCAR 50-year reanalysis: Monthly means CD-ROM and documentation, Bull. Am. Meteorol. Soc., 82, 247-268, 2001.

Liang, X., D. P. Lettenmaier, E. F. Wood, and S. J. Burges, A simple hydrologically based model of land surface water and energy fluxes for general circulation models, J. Geophys. Res., 99, 14,415-14,428, 1994.

Manabe, S., Climate and ocean circulation: 1 . The atmospheric circulation and the hydrology of the Earth's surface, Mon. Weather Rev., 97, 739774,1969

Maurer, E. P., B. Nijssen, and D. P. Lettenmaier, Use of reanalysis land surface water budget variables in hydrologic studies, GEWEX News, 10, 6-8, 2000.

Nijssen, B., R. Schnur, and D. P. Lettenmaier, Global retrospective estimation of soil moisture using the variable infiltration capacity land surface model, 1980-93, J. Clim., 1790-1808, 2001a.

Nijssen, B., G. O'Donnell, D. P. Lettenmaier, D. Lohmann, and E. Wood, Predicting the discharge of global rivers, J. Clim., 14, 3307-3323, $2001 b$.

Pitman, A. J., et al., Key results and implications from phase 1(c) of the Project for Intercomparison of Land-Surface Parameterization Schemes, Clim. Dyn., 15, 673-684, 1999.

Roads, J., and A. Betts, NCEP-NCAR and ECMWF reanalysis surface water and energy budgets for the Mississippi River basin, J. Hydrometeorol., 1, 88-94, 2000.

Sato, N., P. J. Sellers, D. A. Randall, E. K. Schneider, J. Shukla, J. L. Kinter II, Y.-T. Hou, and E. Albertazzi, Effects of implementing the Simple Biosphere Model in a general circulation model, J. Atmos. Sci., 46, 2757-2782, 1989.

Sellers, P. J., Y. Mintz, Y. C. Sud, and A. Dalcher, A Simplified Biosphere Model (SiB) for use within general circulation model, J. Atmos. Sci., 43, $505-531,1986$

Shao, Y., and A. Henderson-Sellers, Modeling soil moisture: A Project for Intercomparison of Land Surface Parameterization Schemes Phase 2(b), J. Geophys. Res., 101, 7227-7250, 1996.

Xie, P., and P. A. Arkin, A 17-year monthly analysis based on gauge observations, satellite estimates, and numerical model outputs, Bull. Am. Meteorol. Soc., 78, 2539-2558, 1997.

Xue, Y., P. J. Sellers, J. L. Kinter, and J. Shukla, A simplified biosphere model for climate studies, J. Clim., 4, 345-364, 1991.

A. Henderson-Sellers and P. Irannejad, ANSTO Environment, PMB 1, Menai, NSW 2234, Australia.

K. McGuffie, Department of Applied Physics, Univ. of Technology, Sydney, P. O. Box 123, Broadway, NSW 2007, Australia. (Kendal. McGuffie@uts.edu.au)

A. J. Pitman, Department Physical Geography, Macquarie Univ., Sydney, Australia. 